\title{
Oral Multifocal Papillary Lesions in a Young Child: Clinico- Pathologic and Medico-Legal Considerations
}

\author{
Liya A. Davidova, Parish P. Sedghizadeh, Amir Balouch, and Hamid Salek* \\ University of Southern California, Orofacial Pain and Oral Medicine Clinic, Los Angeles, California, USA
}

Received: November 20, 2013; Accepted: December 16, 2013; Published: December 19, 2013

"Corresponding author: Hamid Salek, Orofacial Pain and Oral Medicine, , Herman Ostrow School of Dentistry, 925 West 34th St. Los Angeles, California, USA,E-mail: msalek@usc.edu

\begin{abstract}
Human papilloma virus (HPV) is a non-enveloped DNA virus that infects cutaneous and mucosal epithelial cells. Oral lesions of HPV can present as solitary or multifocal lesions, and multifocal lesions can represent a diagnostic challenge clinically with important medicolegal considerations in some cases. We report a unique case of a 12-year-old boy presenting with oral multifocal papillary mucosal lesions which upon biopsy was found to be consistent with a diagnosis of condyloma acuminatum or Heck's disease histopathologically; in situ hybridization studies also confirmed positivity for low risk HPV subtypes in affected tissue. Based on the pathology results and our clinical protocols, we contacted social servicesto rule out the sexually transmitted disease condyloma. A final diagnosis of Heck's disease was rendered after clinico-pathologic and social correlation. Cryotherapy with topical anesthesia was used to successfully treat the lesions with no evidence of recurrence on 6 month follow-up.
\end{abstract}

Keywords: HPV, Heck's disease, condyloma, oral

\section{Introduction}

Human Papilloma Virus (HPV) is a non-enveloped DNA virus that infects cutaneous and mucosal epithelial cells. Oral lesions of HPV can present as solitary or multifocal lesions. Oral HPVassociated lesions include squamous papilloma, condyloma acuminatum, verruca vulgaris, focal epithelial hyperplasia (FEH), Multifocal Epithelial Hyperplasia (MEH or Heck's disease), oral florid papillomatosis (verrucous carcinoma), and a subset of oral squamous cell carcinomas [1,2]. Various modes of transmission for HPV lesions include direct contact such as vertical transmission (periconceptual, prenatal, and perinatal transmission) and horizontal transmission (autoinoculation, heteroinoculation), and indirect contact such as fomite transmission $[3,4]$.

Oral multifocal HPV-positive lesions can present a diagnostic challenge to clinicians because of the potential differential diagnosis. Table 1 summarizes the differential diagnosis and key features related to each condition. Oral HPV infections in children could be of a significant concern to parents and health care providers due to the association of HPV with Sexually Transmitted Diseases (STDs) such as condyloma [5]. Health care providers are mandated in many states including California to report potential sexual child abuse cases to Child Protective
Services (CPS) for further investigation and for ensuring child safety [6]. A diagnosis of HPV-positive multifocal oral lesions in a child could potentially represent condyloma acuminatum or Heck's disease since clinical and histopathology findings and the presence of HPV without specific subtyping are not pathognomonic for either disease. We report a unique case of a 12-year-old boy presenting with oral multifocal papillary mucosal lesions that were confirmed positive for HPV by histopathology and in situ hybridization. California CPS was notified as per our clinical protocols for further investigation.

\section{Case Report}

A 12-year-old Hispanic boy was referred to the Orofacial Pain and Oral Medicine Clinic at the Herman Ostrow School of Dentistry for evaluation of multifocal intraoral lesions. Head and neck examination revealed the presence of multiple asymptomatic, pink to white in color, coalescing lesions of the lower lip, buccal mucosa, and commissures as demonstrated in Figure 1. Some of the lesions appeared sessile, others pedunculated, and others papillary; all had similar and overlapping features. The lesions were not painful and were rubbery soft to palpation. The remainder of the head and neck exam was unremarkable, and a review of systems and medical history were non-contributory. The patient was not taking any medications and the social history was non-contributory. The patient and his mother

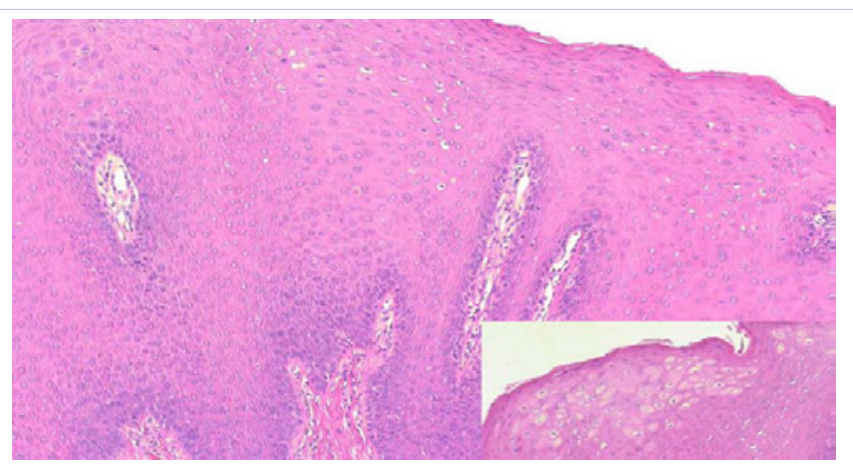

Figure 1: Clinical photograph showing several papillary to pedunculated soft tissue growths affecting the perioral mucosa of a 12-year-old child. 
reported that the onset of the oral lesions was a couple years before presenting to our clinic. No other family members, friends or classmates were affected by the same condition over this period of time. Our clinical differential diagnosis included oral condyloma acuminatum, Heck's disease and less likely oral florid papillomatosis.

The patient's mother consented to biopsy of intraoral lesions for more definitive histopathologic diagnosis. A representative lesion was removed via excisional biopsy with local anesthesia and placed in $10 \%$ formalin for histopathologic diagnosis. HPV in situ hybridization studies were also ordered for the specimen. Routine hematoxylin-eosin stained sections revealed a benign papillary growth of acanthotic and hyperparakeratotic stratified squamous mucosa that exhibited prominent koilocytic change as shown in Figure 2. The lamina propria was comprised of fibrovascular connective tissue which supported a mild chronic inflammatory cell infiltrate. In situ cDNA probe for low-risk HPV subtypes was positive within a subset of the keratinocyte nuclei with appropriate reactivity of positive and negative control tissue. Specific subtyping was not available. The pathology diagnosis was oral condyloma acuminatum or Heck's disease with clinical correlation recommended for more definitive diagnosis.

Due to the results of the pathology report and microscopic diagnosis, combined with clinical findings and history, the patient's mother was questioned regarding possible modes of transmission with respect to HPV in her child. The mother was unsure how her child could have acquired the HPV-positive lesions given that the child's siblings, parents, friends and classmates were not affected by any similar lesions. For the safety of the child and for medico-legal reasons, California CPS was notified for further evaluation and to rule out condyloma or potential child sexual abuse. CPS investigations involved interviewing the family, child and health care providers and official statements were taken. CPS concluded after weeks of investigation that sexual abuse was not likely and the patient was in a safe and healthy home and school environment.

Cryotherapy with topical anesthesia was used to treat the lesions and consisted of using a metal probe to apply liquid nitrogen to theoral lesions one by one. A 20 second freeze per lesion was maintained during initial treatment, followed by a 30 second freeze during the second visit two weeks later, and a 40 second freeze per lesion during the third and final visit another two weeks later. With the 40 second application there was slight post-operative edema which resolved without intervention after a couple of days. Improvement of treated lesions became evident two weeks after the initial treatment (during the second treatment visit) and more improvement and resolution of affected areas was noted during subsequent appointments as shown in Figure 3. Lesions resolved by 6-month follow-up and the patient reported no pain or adverse reactions associated with the therapy.

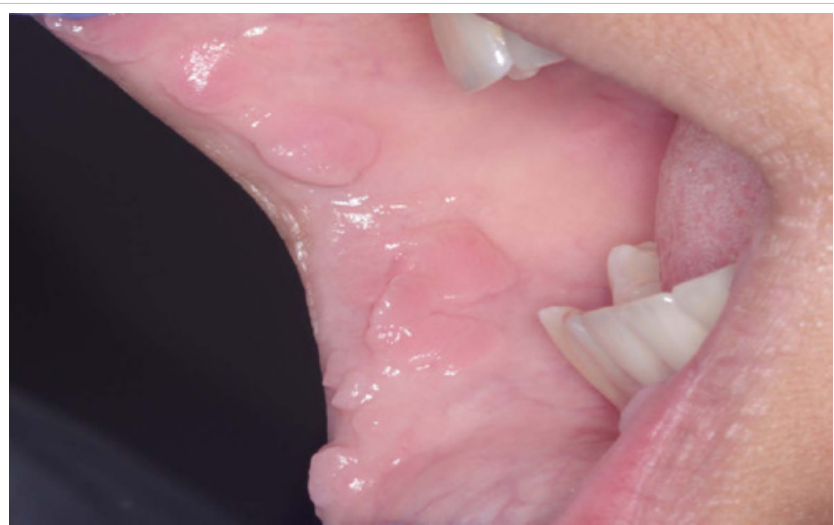

Figure 2: Photomicrograph of biopsy tissue demonstrating a benign proliferation of acanthotic and hyperkeratotic stratified squamous oral epithelium with central fibrovascular cores characteristic of condyloma acuminatum (H\&E, 20x original magnification). The inset in the lower right reveals prominent koilocytic change with hyperchromatic nuclei and perinuclear halos (H\&E, 40x original magnification).

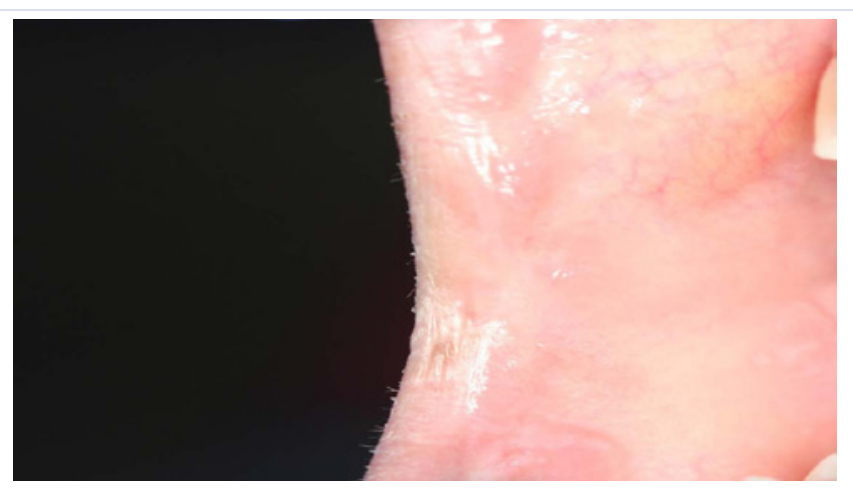

Figure 3: Clinical photograph at 6 month follow-up shows resolution of lesions following cryotherapy.

\section{Discussion}

There are over 140 HPV genotypes, and at least 30 of them have been detected in the oral cavity; HPV subtypes can be classified as low-risk (non-oncogenic strains: 2, 3, 4, 6, 7, 10, 11, $13,32,40,57$ ) and high-risk (oncogenic strains: 16, 18, 31, 33, $35,45,52,58,59,68)[5,7,8]$. Low-risk types are associated with benign lesions such as Heck's disease (types 13,32), condyloma acuminatum (types 6,11), squamous cell papilloma, and verruca vulgaris (types 2,4). High-risk types can be associated with oral condyloma (types 16,18 ) in some cases, and also malignancies in the oral cavity such as squamous cell carcinoma and oral florid papillomatosis [7].

HPV-positive multifocal oral lesions consistent with condyloma acuminatum or Heck's disease are an uncommon finding in young children and are rarely reported. In the currently reported case, the diagnosis of Heck's disease is the most likely diagnosis given the clinical, histopathologic, HPVin situ hybridization, and social services findings. We were limited in more definitive diagnosis by the fact that we did not have 
Table 1:

\begin{tabular}{|c|c|c|}
\hline Disease & Etiology & Histopathology \\
\hline Focal epithelial hyperplasia (Heck's Disease) & $\begin{array}{l}\text { HPV (HPV types } 13 \text { or } 32 \text { predominantly } \\
\text { detected) }\end{array}$ & $\begin{array}{l}\text { Epithelial hyperplasia andacanthosiswithhydropic } \\
\text { Degeneration; rete ridges are joined and the oral } \\
\text { mucosal surface isparakeratinized. }\end{array}$ \\
\hline Condyloma acuminatum & $\begin{array}{l}\text { HPV (HPV types } 6 \text { and } 11 \text { predominantly } \\
\text { detected) }\end{array}$ & $\begin{array}{l}\text { Exuberant squamous proliferation with verruciform and } \\
\text { papillary architecture; papillary projections contain a } \\
\text { fibrovascular core. }\end{array}$ \\
\hline Squamous papilloma & $\begin{array}{l}\text { HPV in some cases (HPV types } 6 \text { and } 11 \\
\text { predominantly detected) }\end{array}$ & $\begin{array}{l}\text { Solitary proliferation of keratinized stratified squamous } \\
\text { epithelium oriented in finger-like projections with } \\
\text { fibrovascular connective tissue cores. }\end{array}$ \\
\hline Inflammatory fibrous hyperplasia & Trauma and Candida infection implicated & $\begin{array}{l}\text { Papillary pattern of mucosal proliferation with } \\
\text { pseudoepitheliomatous hyperplasia and marked chronic } \\
\text { inflammatory cell infiltrates. }\end{array}$ \\
\hline Verruciform xanthoma & $\begin{array}{l}\text { Trauma, viruses such as HPV, and impaired } \\
\text { immune response implicated }\end{array}$ & $\begin{array}{l}\text { Focal parakeratosis, mild epithelial hyperplasia with } \\
\text { regularly elongated rete ridges, and xanthoma cells in } \\
\text { the papillary dermis. }\end{array}$ \\
\hline Inflammatory papillary hyperplasia & Trauma and Candida infection implicated & $\begin{array}{l}\text { Papillary mucosal } \\
\text { projections covered with parakeratotic stratified } \\
\text { squamous epithelium with inflammatory infiltration of } \\
\text { the connective tissue. }\end{array}$ \\
\hline Verrucous carcinoma & HPV and EB viruses implicated & $\begin{array}{l}\text { Wide and elongated epithelial rete ridges with a } \\
\text { papillary or verruciform surface; parakeratin filled clefts } \\
\text { between surface epithelial projections, and lesional cells } \\
\text { do not display striking atypia. }\end{array}$ \\
\hline
\end{tabular}

specific HPV subtyping available to us, which is common with respect to many oral pathology laboratories since HPV subtyping is not routinely performed beyond determining a low risk versus high risk panel. For accurate diagnosis in the currently reported case, due diligence mandated ruling in or ruling out possible sources of transmission in our patient. Vertical transmission from mother to child could obviously be ruled out, family or social transmission could be ruled out based on history and findings; therefore our dilemma was whether there was direct horizontal transmission such as sexual or non-sexual heteroinoculation, or indirect transmission via fomites. Although Heck's diseaseis the likely diagnosis in this case, the mode of transmission remains uncertain.

More recent literature suggests the possibility of oral HPV infection as a result of direct personal contact between family members or indirect contact (fomite transmission) $[9,10]$. Mantet al even suggested that HPV infection could be acquired from peers by horizontal transmission [11]. Recently there is more evidence of oral HPV transmission in children and adolescents through close personal contact anywhere from shared toys and eating utensils to kissing and bathing [10]. In our case, indirect transmission via fomites is likely with possible direct autoinoculation to multiple sites in the mouth following oral trauma or biting.

Various treatment methods have been proposed for HPV lesions, among them are scalpel surgery, cryotherapy, laser ablation, electrocoagulation, and topical treatments [9]. An abundant amount of literature is available on the use of cryotherapy for treatment of cutaneous [12] and anogenital warts $[9,13-16]$. Within this small spectrum of reports even fewer studies have been published about cryotherapy use for treatment of oral condyloma acuminatum. For treatment in our case, cryotherapy was chosendue to it being advantageous for diffuse or multifocal lesions, less aggressive than surgery of multiple sites, non-aerosolizing like some laser surgeries, and resulting in minimal to no pain or scarring $[8,17]$.

Since multifocal papillary oral mucosal lesions such as condylomaan be related to sexual abuse, accurate definitive diagnosis is imperative especially in children $[2,18]$. As health care providers we are responsible for reporting cases of suspected child abuse to social services, in order for them to take appropriate measures to investigate the matter and protect the child, if necessary. Therefore, familiarity by our profession with the presentation and modes of transmission of oral multifocal HPV-positive lesions, particularly in children, is essential to accurate diagnosis, child safety and management.

\section{References}

1. Mannarini, L., Kratovchil, V., Calabrese, L., Gomes Silva, L., Morbini, P., Betka, J., et al. (2009). Human Papilloma Virus (HPV) in Head and Neck Region: review of Literature. Acta Otorhinolaryngol Ital, 29(3), $119-26$.

2. Pinheiro, R. S., de Franca, T., Ferreira, D., Ribeiro, C., Leao, J., \& Castro , G. (2011). Human papillomavirus in the oral cavity of children. J Oral Pathol Med, 40(2), 121-6.

3. Mammas, I. N., Sourvinos, G., Giamarelou, P., Michael C., \& Spandidos, D. A. (2012). Human papillomavirus in the oral cavity of children and mode of delivery: a retrospective study. Int J STD AIDS, 23(3), 185-8.

4. Syrjanen, S. (2010). Current concepts on human papillomavirus infections in children. APMIS, 118(6-7), 494-509.

5. Rautava, J., \& Syrjanen, S. (2011). Human papillomavirus infections in 
the oral mucosa. J Am Dent Assoc, 142(8), 905-14.

6. U.S. Department of Health and Human Services Administration for Children \& Families. (n.d.). Child Sexual Abuse: Intervention and Treatment Issues: Investigation of Child Sexual Abuse. Retrieved December 27, 2012, from Child Wellfare Information Gateway.

7. Sanders, A., Slade, G. D., \& Patton, L. L. (2012). National prevalence of oral HPV infection and related risk factors in the U.S. adult population. Oral Dis, 18(5), 430-41.

8. Lipke, M. M. (2006). An Armamentarium of Wart Treatments. Clin Med Res, 4(4), 273-93.

9. Culton, D., Morrell, D., \& Burkhart, C. (2009). The management of condyloma acuminata in the pediatric population. Pediatr Ann, 38(7), 368-72.

10. Flake, C., Arafa, J., Hall, A., Ence, E., Howard, K., \& Kingsley, K. (2012) Screening and detection of human papillomavirus (HPV) high-risk strains HPV16 and HPV18 in saliva samples from subjects under 18 years old in Nevada: a pilot study. BMC Oral Health, 12(43).

11. Mant, C., Kell, B., Rice, P., Best, J. M., Bible, J. M., \& Cason, J. (2003) Buccal exposure to human papillomavirus type 16 is a common yet transitory event of childhood. J Med Virol, 71(4), 593-8.

12. Bruggink, S. C., Gussekloo, J., Berger, M., Zaaijer, K., Assendelft, W., W.M de Waal, M., et al. (2010). Cryotherapy with liquid nitrogen versus topical salicylic acid application for cutaneous warts in primary care: randomized controlled trial. CMAJ, 182(15), 1624-30.

13.Stefanaki, C., Katzouranis, I., Lagogianni, E., Hagjivassiliou, M., Nicolaidou , E., Panagiotopoulos , A., et al. (2008). Comparison of cryotherapy to imiquimod $5 \%$ in the treatment of anogenital warts. Int J STD AIDS, 19(7), 441-4.

14. Gilson, R. J., Ross, J., Maw, R., Rowen, D., Sonnex, C., \& Lacey, C. (2009). A multicentre, randomised, double-blind, placebo controlled study of cryotherapy versus cryotherapy and podophyllotoxin cream as treatment for external anogenital warts. Sex Transm Infect, 85(7), 514-9.

15. Mi, X., Chai, W., Zheng, H., Zuo, Y.-G., \& Li, J. (2011). A randomized clinical comparative study of cryotherapy plus photodynamic therapy vs. cryotherapy in the treatment of multiple condylomata acuminata. Photodermatol Photoimmunol Photomed, 27(4), 176-80.

16. Hathaway, J. K. (2012). HPV: Diagnosis, Prevention, and Treatment . Clin Obstet Gynecol, 55(3), 671-80.

17. Farah, C., \& Savage, N. (2006). Cryotherapy for treatment of oral lesions. Aust Dent J, 51(1), 2-5.

18. Mendez-Mendoza, A., Ledesma-Montes, C., \& Garces-Ortiz, M. (2012). Multifocal Epithelial Hyperplasia. N Am J Med Sci, 4(10), 510-11. 